\title{
Desafios e dilemas dos grandes países periféricos: Brasil e Índia
}

\section{SAMUEL PINHEIRO GUIMARÃES*}

\section{Introdução}

Este artigo argumenta que se, por um lado, Brasil e Índia apresentam significativas diferenças como sociedades e Estados, o que explicaria o histórico isolamento recíproco, caracterizado pela fragilidade de vínculos políticos e econômicos, ${ }^{1}$ por outro, situam-se numa categoria especial quando se examina o conjunto de países que constituem a periferia do sistema político e econômico capitalista mundial.

Essa categoria, a que pertenceriam a Índia e o Brasil, e a que denominamos nesse artigo de "grandes países periféricos", defronta-se com um cenário internacional, resultado de um longo processo histórico, organizado em torno do que são conceituadas, no artigo, como "estruturas hegemônicas de Poder".

O artigo descreve as características desse cenário, suas contradições principais, as estratégias de preservação e expansão de poder daquelas estruturas hegemônicas e, por fim, sugere objetivos estratégicos que o Brasil e a Índia, como grandes países periféricos, deveriam procurar atingir. Os desafios para os grandes países periféricos são superar tanto as vulnerabilidades externas quanto as disparidades internas e construir a democracia real e, assim, serem capazes de vir, ou virem, a integrar aquelas estruturas ou deixarem de estar a elas subordinados. O dilema é que ou enfrentam esses desafios, e para tal terão um relacionamento complexo, tenso e difícil com aquelas estruturas, ou permanecerão em situação de crescente inferioridade, devido à concentração de poder econômico, político e militar, e enfrentarão um processo de desagregação econômica interna, de instabilidade política e de eventual fragmentação territorial.

\section{Contrastes: Brasil e Índia}

Brasil e Índia são sociedades e Estados que exibem extraordinárias diferenças. A Índia é uma sociedade de civilização oriental, multimilenar e 
consolidada; já o Brasil é uma sociedade de raízes ocidentais, recentíssima e em formação. Ambas sujeitas ao impacto ininterrupto das idéias, dos costumes e das políticas geradas no centro da sociedade internacional, difundido pelos meios globais de comunicação: porém, sociedades isoladas entre si.

A Índia é o berço de religiões e filosofias e o Brasil um país puramente importador de ideologias ocidentais. As religiões e filosofias da Índia correspondem a uma sociedade multirracial, de numerosos idiomas e dialetos, de desigualdades de gênero e de classe, estratificadas por costumes milenares, com poderosos conflitos latentes. O Brasil, sociedade de origens plurirraciais, miscigenada, na qual a origem étnica ou religiosa por si só não "classifica”, ${ }^{2}$ caracteriza-se pelo idioma único e pela ausência de conflitos territoriais.

Tanto a Índia como o Brasil apresentam extraordinárias disparidades de renda e de propriedade, de riqueza e de pobreza, de cultura e de barbárie. O Brasil, apesar disto e talvez pela sua história recente, apresenta um grau mais elevado de mobilidade social e espacial.

A Índia, ou melhor, os diversos Estados que vieram a constituir a Índia, correspondiam a sociedades milenares e a Estados estruturados quando foram invadidos e conquistados por uma potência ocidental que se tornaria hegemônica, a Grã-Bretanha. ${ }^{3}$ As populações autóctones brasileiras, reduzidas e dispersas em vasto território, de organização social e política primitiva, sem linguagem escrita, foram dominadas por uma potência européia, Portugal, que não superou a etapa mercantil de sua evolução capitalista, que rapidamente se colocou sob a proteção inglesa e que estruturou o Brasil como parte do sistema político colonial.

A Índia, após uma longa e notável luta anticolonialista, atinge sua independência em 1947 e se encontra, naquele momento, distante geograficamente do novo centro hegemônico de poder, os Estados Unidos; porém, cercada de Estados hostis ou poderosos. O Brasil transitou de uma situação colonial para a independência por um ato de outorga política e se manteve dentro da mesma esfera de influência hegemônica a que se ligava anteriormente, por meio de Portugal. Distante de seus vizinhos pela floresta e pelas amplas regiões desabitadas, enfrentou e enfrenta rivalidades, em menor grau, ao sul, no Rio da Prata, mas se encontra, desde sua origem, na zona geográfica de influência da que viria a ser a principal potência atual, os Estados Unidos.

A Índia é uma democracia parlamentar que, apesar das disparidades econômicas, das tensões religiosas e étnicas e dos conflitos externos, não sucumbiu ao autoritarismo militar, mesmo tendo forças armadas adestradas, numerosas e aguerridas. O Brasil, a despeito de tensões internas e externas muito inferiores às que têm ocorrido na Índia, sofreu, durante vinte anos, somente no período posterior à Guerra, com o autoritarismo, militar e civil.

A Índia, por sua tradição de luta anticolonial, anti-racista, pacifista e desarmamentista, esteve à frente do Movimento Não-Alinhado (MNA) que se 
inaugura, em 1955, com a Conferência de Bandung. O Brasil não participou do MNA e exercitou uma política exterior que oscilou entre períodos de alinhamento ocidental e, por vezes, anticomunista militante, e períodos de razoável independência, mas sem chegar ao não-alinhamento.

\section{Brasil e Índia: grandes países periféricos}

Apesar dessas notáveis diferenças, Brasil e Índia compartilham semelhanças e interesses comuns por serem "grandes países periféricos”, o que os distingue radicalmente dos países médios e pequenos da periferia. Grandes países periféricos seriam aqueles países não-desenvolvidos, de grande população e de grande território contínuo, não-inóspito, razoavelmente passível de exploração econômica.

A importância econômica efetiva de uma grande população depende de seu nível educacional, de saúde e de sua produtividade (que depende, por sua vez, do estoque de capital) e, portanto, de sua renda. Ainda quando os indicadores de educação, saúde e produtividade desses países não são altamente positivos, é inegável que uma população numerosa, num território extenso, traz, em si, um grande potencial econômico, científico-tecnológico, militar e político.

A população numerosa possibilitaria, em princípio, desenvolver um maior número de atividades produtivas e, em cada uma delas, atingir escalas econômicas mínimas de produção. Do mesmo modo, a existência de um mercado interno mais amplo, diversificado e dinâmico pode reduzir a importância do mercado externo, a vulnerabilidade do sistema econômico a choques exógenos e, em conseqüência, pode reduzir a possibilidade de oscilações bruscas nos níveis de bem estar da população e em sua trajetória de desenvolvimento.

A ocorrência de indivíduos altamente dotados - a despeito de depender para se efetivar de fatores como níveis de escolaridade e renda - cresce com a população, gerando efeito importante sobre as atividades de pesquisa científica e tecnológica. Estas, por sua vez, são atividades sujeitas a economias de escala e necessitam de um mercado garantido mínimo estável para aumentar a probabilidade de recuperação dos investimentos feitos. Tais investimentos são de alto risco, devido ao custo dos equipamentos sofisticados, da aleatoriedade de resultados e do tempo longo de maturação. Por outro lado, a atividade militar moderna depende cada vez mais da pesquisa científica e tecnológica para o desenvolvimento de seus armamentos. Sem uma razoável autonomia quanto ao suprimento doméstico e capacidade de aperfeiçoamento do equipamento bélico latu sensu, qualquer organização militar está sujeita a "estrangulamento" externo pela interrupção do suprimento de peças de reposição e de munição. ${ }^{4}$

O território extenso e passível de exploração econômica implica a possibilidade de ocorrência de maior variedade de recursos minerais, de maior 
biodiversidade, de produção agrícola diversificada, de maior necessidade de pesquisa e atividade espacial, de telecomunicações e aeronáutica, áreas de ponta do desenvolvimento tecnológico e econômico. Estas potencialidades, caso exploradas, acarretam menor dependência (da sociedade em território extenso) em relação ao abastecimento externo de energia, de alimentos e de insumos industriais. Uma menor dependência, agregada à maior importância relativa do mercado interno, pode reduzir não só a vulnerabilidade do sistema econômico a choques externos mas também sua vulnerabilidade a pressões políticas e militares exógenas.

O desenvolvimento de todas as potencialidades decorrentes de população numerosa e de território extenso traria efeito notável sobre o potencial militar e sobre a capacidade de exercer influência política nos âmbitos regional e mundial.

São essas potencialidades para promover maior acumulação de capital, desenvolvimento científico e tecnológico, produção e produtividade, capacidade militar convencional e não-convencional, competitividade ampla e diversificada em nível internacional, com menor vulnerabilidade a choques e pressões externas, que distinguem os grandes países periféricos dos demais países da periferia.

Os países médios, mas muito especialmente os pequenos Estados da periferia, ainda que sejam capazes de acumular capital, desenvolver tecnologia e alcançar níveis de bem-estar elevados, terão, devido às limitações de sua população e território, de desenvolver graus mais elevados de especialização produtiva e de depender em maior medida de insumos e de bens finais do mercado mundial e de nele colocar parcela maior de sua produção. Por este motivo, os países médios, e ainda mais os pequenos, mini e micro-Estados, estarão mais sujeitos a choques, naturais ou artificiais, e a pressões externas tanto políticas como econômicas, sendo mais vulneráveis e dependentes das estruturas hegemônicas de Poder e mais sujeitos aos efeitos da evolução dos grandes fenômenos que caracterizam o cenário internacional.

\section{As estruturas hegemônicas de Poder}

O cenário e a dinâmica internacional em que atuam os grandes países periféricos não são novos e imparciais, e as sociedades, os Estados e os Governos nunca iniciam sua atuação internacional a partir da "estaca zero", com os mesmos direitos, deveres e iguais oportunidades. Apesar do que parece ser a opinião de alguns analistas, estes não são cenário e dinâmica em que os Estados, ao sabor dos ventos e com plena independência, organizam alianças e participam de estruturas, escolhendo, a cada momento, seus aliados para atingir seus objetivos.

O cenário internacional, com que se defrontam qualquer sociedade, Estado e governo, organiza-se em torno de estruturas hegemônicas de Poder, político e econômico. Essas estruturas, resultado de um processo histórico, beneficiam os países que as integram e têm como principal objetivo sua própria perpetuação. 
O conceito de estruturas hegemônicas é preferível ao de Estado hegemônico. Por Estado hegemônico se pode entender aquele Estado que, em função de sua extraordinária superioridade de poder econômico, político e militar em relação aos demais Estados, está em condições de organizar o sistema internacional, em seus diversos aspectos, de tal forma que seus interesses, de toda ordem, sejam assegurados e mantidos, se necessário pela força, sem Poder ou coalizão de Poderes que possa impedi-lo de agir. Seria, por exemplo, a situação dos Estados Unidos após a Segunda Guerra Mundial. Poder-se-ia “atenuar” alguns dos aspectos dessa definição ou incluir a idéia de que o Estado se caracteriza como hegemônico na medida em que tem condições de abdicar de algumas vantagens que sua situação lhe confere no interesse maior de garantir o conjunto de seus interesses a longo prazo. É o que teriam feito os Estados Unidos em relação ao Japão, permitindo uma política protecionista japonesa enquanto abriam seu mercado aos produtos japoneses e, de forma semelhante, quanto à sua aceitação do projeto europeu de constituição de uma Comunidade Econômica Européia.

Segundo alguns analistas, por não existir hoje um Estado claramente hegemônico, o cenário internacional poderia ser melhor descrito como apresentando uma unipolaridade (hegemonia) militar americana; uma multipolaridade (ausência de hegemonia) econômica competitiva, em torno da chamada "tríade": Estados Unidos, Japão e União Européia; e um condomínio político exercido pelos membros permanentes do Conselho de Segurança das Nações Unidas.

Outros analistas insistem em que o papel dos Estados é cada vez menor no cenário internacional e que estariam eles sendo, crescente e rapidamente, substituídos por empresas multinacionais, transnacionais, globais, que “eliminariam”, na prática, as fronteiras e que desconsiderariam as legislações e políticas nacionais, de qualquer Estado e, com maior razão, dos Estados periféricos.

Essa visão esquece que os interesses econômicos das grandes empresas sempre estiveram vinculados aos Estados, de uma forma ou de outra, desde o Comitê dos XXI da República Holandesa até as grandes companhias inglesas de comércio e as transnacionais americanas de hoje. Todavia, as grandes empresas atuais não têm como se transformar em organismos legislativos e sancionadores legítimos, isto é, aceitos pela sociedade, que serão sempre indispensáveis enquanto houver competição e conflito entre empresas, classes, grupos sociais, étnicos, religiosos etc. As funções precípuas do Estado, além da defesa do território e de sua soberania, são legislar, isto é, criar normas de conduta; sancionar, isto é, punir os violadores dessas normas; dirimir conflitos sobre sua interpretação, e, afinal, defender os interesses de seus nacionais e de suas empresas quando estas se encontram sob jurisdição estrangeira. Tais funções não se confundem com as funções da "empresa”, que são produzir e distribuir bens de forma privada, a partir do mercado. A emergência de agências supranacionais, estruturas de natureza estatal, não extingue, nem modifica a necessidade daquelas funções do Estado, 
nem invalida o raciocínio acima. No passado, como o caso da Alemanha ilustra, pequenos Estados soberanos ou semi-soberanos se uniram para formar entes estatais maiores e assim melhor defender os interesses públicos e privados dos membros de sua sociedade, indivíduos ou pessoas jurídicas. Portanto, o fenômeno "supranacional” não é novo.

O conceito de "estruturas hegemônicas de Poder" evita discutir a existência ou não, no mundo pós-Guerra Fria, de uma potência hegemônica, os Estados Unidos, e determinar se o mundo é unipolar ou multipolar, se existe um condomínio ou não. O conceito de "estruturas hegemônicas” é mais flexível e inclui vínculos de interesse e de direito, organizações internacionais, múltiplos atores públicos e privados, a possibilidade de incorporação de novos participantes e a elaboração permanente de normas de conduta; mas no centro dessas estruturas estão sempre Estados nacionais.

As estruturas hegemônicas, cuja liderança varia de acordo com o espaço geográfico, o momento e o tema em questão, desenvolvem estratégias de preservação de seu poder econômico e tecnológico, político, militar e ideológico. Têm elas sua origem na expansão econômica e política da Europa, que se inicia com a formação dos grandes Estados nacionais. Na Espanha, com a conquista de Granada e a expulsão dos mouros (1492); na França, com o fim da Guerra de Cem Anos (1453), a expulsão dos ingleses, e a criação por Henrique IV do Estado unitário francês; e na Inglaterra, a partir da Rainha Elisabeth I (1558-1603). A expansão européia se acelera com o ciclo das descobertas após a queda de Constantinopla (1453) que força a busca de rota marítima para o Oriente e a decorrente expansão mercantil e acumulação de riqueza com a formação dos impérios coloniais, a partir de Cortez (1521) e de Pizarro (1533), e, no Brasil, a partir da cana de açúcar em Pernambuco. A revolução tecnológica, militar e industrial dos séculos XVIII e XIX, a partir da máquina a vapor (precondição da indústria, ao substituir a força animal, hidráulica e eólica por uma fonte de energia permanente, regulável e estável), consolida a supremacia européia no cenário internacional.

A dinâmica dos ciclos de acumulação capitalista e das relações entre o grande capital privado e o Estado e entre tecnologia, forças armadas e sociedade explicam, em grande parte, os processos de formação das estruturas hegemônicas de Poder. Esses processos passaram, entre 1917 e 1989, por uma fase crucial, de disputa com o modelo socialista alternativo de organização da sociedade e do Estado, interrompida pelo conflito, surgido no interior da própria estrutura, com os Estados contestatários, a Alemanha e o Japão (1939-1946).

Superada essa fase crucial, as estruturas hegemônicas vêm procurando consolidar sua extraordinária vitória ideológica, política e econômica, por meio da expansão de sua influência e ação sobre os territórios que estiveram, até recentemente, sob organização socialista (Europa Oriental, ex-União Soviética, 
países socialistas asiáticos) e sobre aqueles territórios da periferia aos quais haviam taticamente permitido “desvios” de organização econômica e política (e. g., Estadoempresário, planejamento da economia pelo Estado) no período mais acirrado da disputa com o modelo socialista alternativo.

\section{A primeira estratégia: a criação de agências internacionais}

As estratégias de preservação e de expansão do poder dessas estruturas nessas "novas" áreas territoriais se desenvolvem em vários domínios e utilizam diversas táticas e instrumentos.

No passado, as diferenças de poder econômico e político dentro das sociedades eram justificadas pelas classes dominantes como decorrentes da vontade divina. A partir de Locke e das revoluções francesa e americana tais diferenças passaram a ser explicadas como resultado das variações da capacidade "natural” entre etnias e classes sociais e o poder político se organizou com base na propriedade e na riqueza. As diferenças de prosperidade e de riqueza continuaram a ser "explicadas" como decorrentes, de certa forma, de vontade divina, como na teoria da predestinação e da riqueza como evidência do favor divino, centrais na ética protestante.

Tais teorias repercutiam no cenário internacional, justificando o comportamento dos Estados europeus em seu relacionamento com as sociedade "infiéis” e "atrasadas" da periferia que deveriam ser conquistadas para o "cristianismo" e para a "civilização". Na área internacional, as estruturas hegemônicas se organizaram, após o Congresso de Viena (1815), mais ou menos informalmente (por meio das reuniões do Concerto das Nações; da Santa Aliança; dos sistemas de alianças conhecido como "equilíbrio de poder" na Europa) enquanto agiam pela força, direta, ostensiva, e às vezes de forma coordenada, em zonas da periferia para incorporá-las como colônias ou para subjugar revoltas contra seus interesses como a história da expansão européia na África e na Ásia, e, em especial, na China, bem exemplifica.

Todavia, com o desenvolvimento das lutas sindicais, humanitárias e anticolonialistas, as ideologias “desiguais” foram progressivamente substituídas por ideologias "igualitárias" dentro das sociedades e entre os Estados (igualdade soberana dos Estados e autodeterminação dos povos), em especial a partir da Revolução Bolchevique e dos 14 Pontos de Wilson que foram a ela uma tentativa de resposta. Diante dessa nova realidade, que impedia, ou, pelo menos, dificultava o uso direto da superioridade e da força militar e econômica, as estruturas hegemônicas de Poder procuraram criar organizações internacionais por meio das quais pudessem preservar o seu poder no âmbito internacional e legitimá-lo aos olhos de sua opinião pública nacional, inspirada agora por uma visão do mundo igualitária. Assim, as estruturas hegemônicas de Poder, sob a liderança dos Estados 
Unidos, (após a grave crise interna de contestação de liderança de 1914 a 1919) criaram a Sociedade das Nações, que não teve o sucesso esperado e, após a crise de 1939 a 1945, a Organização das Nações Unidas, como centro de um sistema de agências internacionais nos mais diversos campos de atividade desde os refugiados, à saúde, às telecomunicações, à agricultura, à energia nuclear etc.

A primeira estratégia de preservação e expansão das estruturas hegemônicas de Poder se verifica através da expansão das organizações internacionais sob seu controle, tais como o Conselho de Segurança, centro de poder efetivo das Nações Unidas; a Organização do Tratado do Atlântico Norte (OTAN); a Agência Internacional de Energia Atômica (AIEA); o Grupo dos Sete (G-7); a Organização Mundial do Comércio (OMC); a União Européia; o North America Free Trade Agreement (NAFTA); a Organização de Cooperação e Desenvolvimento Econômico (OCDE); o Fundo Monetário Internacional (FMI) etc.

No seio de tais organizações, se desenvolve, sob a liderança dos países que integram aquelas estruturas hegemônicas, um esforço de elaboração de normas, com suas respectivas sanções, de comportamento internacional (e, hoje, crescentemente nacional) "permitido”, legítimo. A participação da maioria dos países da periferia não só é considerada essencial, como chega a ser "exigida” não para que tomem parte efetivamente da elaboração daquelas normas mas, sim, para dar legitimidade e validade universal a tais normas e à aplicação de suas eventuais sanções.

De um lado, essas normas de conduta refletem a força relativa dos diversos integrantes daquelas estruturas hegemônicas e regulam suas relações dentro das estruturas. De outro lado, tais normas enquadram os Estados da periferia, buscando sempre o objetivo maior de preservação das estruturas, de seu poder e dos benefícios delas decorrentes para as sociedades dos Estados centrais que as integram.

No âmbito político, busca-se a expansão da competência do Conselho de Segurança das Nações Unidas e de seu sistema de sanções para além do conceito inicial restrito, conforme a Carta de São Francisco, de ameaça à paz e de ruptura da paz. No âmbito militar se verifica, de um lado, a preservação do status especial dos integrantes daquelas estruturas e, de outro, a elaboração de normas de controle da difusão de tecnologias avançadas, por meio da AIEA, do Tratado de NãoProliferação Nuclear (TNP), do Comprehensive Test Ban Treaty (CTBT), da Organização para Eliminação de Armas Químicas (OPAQ), dos acordos de Wasenaar, do Missile Technology Control Regime (MTCR) etc. Finalmente, procurase a coordenação de ações militares usando a OTAN, a inclusão de novos membros na OTAN e a ampliação de sua esfera geográfica de atuação.

A elaboração de normas de conduta econômica na esfera internacional e na doméstica para um número crescente de atividades se realiza no âmbito de várias organizações internacionais. Os principais foros onde se elaboram tais normas 
são a OCDE e a OMC, e se utiliza para sua implementação o sistema de "condicionalidades” do FMI e do Banco Mundial, em especial para os países endividados da periferia. Outras arenas de elaboração de normas são as estruturas supranacionais, como a União Européia, que incluem um número crescente de países europeus e o esquema da Cúpula de Miami, que pretende negociar ampla gama de compromissos políticos e na área econômica criar a Área de Livre Comércio das Américas (ALCA). A própria negociação da ALCA viria a definir e consolidar normas de política econômica para todos os países do Hemisfério Ocidental, em especial os de natureza periférica.

\section{A segunda estratégia: cooptação e fragmentação}

A segunda estratégia de preservação das estruturas hegemônicas de Poder é a de incluir novos atores, como sócios menores, por conveniência tática ou devido à necessidade de refletir novas realidades de poder, decorrentes da dinâmica internacional.

Exemplos recentes dessa estratégia são a incorporação da Rússia ao G-7; a proposta de inclusão da Alemanha e do Japão no Conselho de Segurança das Nações Unidas; a expansão da União Européia pela incorporação de pequenos e médios países da Europa; a incorporação de Estados da Europa Oriental à OTAN e a expansão de sua área geográfica de atuação; a incorporação do México à Free Trade Area (FTA) entre o Canadá e os Estados Unidos, criando o NAFTA; e a admissão da China à OMC.

A outra face dessa estratégia de cooptação corresponde a um vigoroso e, eventualmente, violento processo de isolamento e de sanção de eventuais contestadores do poder das estruturas hegemônicas, podendo ser citados como exemplos mais flagrantes os casos de Cuba, do Vietnã, do Iraque e dos países muçulmanos fundamentalistas não cooptados.

No processo estratégico de preservação, expansão e perpetuação de poder dessas estruturas hegemônicas, a eventual divisão interna e fragmentação territorial de terceiros Estados, em especial dos grandes Estados da periferia, é vista, quando não promovida, com favor e interesse, ainda que com natural discrição. Assim, a fragmentação da União Soviética, da Iugoslávia, e a perspectiva de fragmentação da República Popular da China foram e são vistas com beneplácito, quando não estimuladas.

Por outro lado, os processos de fortalecimento e de coordenação política e econômica dentro e, especialmente, fora das estruturas hegemônicas de Poder são vistos com desconfiança e, a partir de certos pontos-limite, com antagonismo, como ocorreu com a União Européia e, mais recentemente, com o Mercosul, enquanto não são enfraquecidos ou cooptados por aquelas estruturas. 
Grandes Estados da periferia, como o Brasil e a Índia, sempre que se engajam em programas de fortalecimento político, econômico, militar ou tecnológico de natureza autônoma são vistos com suspeita, ameaçados e até atingidos por sanções. Por outro lado, a eventual fragmentação de seu território ou a criação de tensões internas através de iniciativas que incentivam a reivindicação de territórios autônomos para minorias, que estimulam o fortalecimento de diferenças raciais e a ação de seitas fundamentalistas agressivas, seriam processos que contribuiriam para, ao menos, enfraquecer a coesão interna dos grandes Estados da periferia e, assim, para o êxito da estratégia de preservação de poder daquelas estruturas hegemônicas.

A terceira estratégia: geração de ideologias

Na estratégia de preservação de poder têm grande, crescente e pouco examinada relevância os instrumentos de geração ideológica das estruturas hegemônicas de Poder para a população de todos os países, quer pertençam eles ao seu centro, quer se situem em sua periferia. O processo de elaboração de conceitos, de visões do mundo e de situações específicas, que chamaremos aqui de "ideologias", se desenvolve em diversos níveis e se utiliza de distintos instrumentos.

Sua validade, sua utilidade para a preservação e a perpetuação das estruturas hegemônicas de Poder depende de serem tais "ideologias” percebidas como neutras, desinteressadas, ou melhor ainda, de interesse geral, imparciais, verídicas e verossímeis. Muitas dessas ideologias, justamente por não terem tais características, vêm a ser desmentidas pela realidade. Sempre que isto ocorre, são substituídas por outras ideologias que as desmentem, ridicularizam e se apresentam como "novas" e, agora, "verdadeiras".

Assim, sua elaboração conceptual e seu foco central, inicial, de difusão, deve se localizar acima dos Governos e dos Estados nacionais. Seu locus ideal se encontra, portanto, nos quadros técnicos das organizações internacionais de âmbito mundial, supostamente imparciais e independentes daqueles Governos e Estados. As grandes organizações de composição mundial, tais como o Fundo Monetário Internacional, o Banco Mundial, a Organização Mundial do Comércio, exercem um papel estratégico fundamental no processo de elaboração de ideologias e de sugestões de políticas a serem seguidas, em especial pelos Governos de Estados periféricos já que, por razões óbvias, os Governos dos países centrais não levam em consideração as sugestões de políticas quando são, eventualmente, feitas por tais agências.

O controle do processo de geração de ideologias nessas organizações, que se realiza em seus quadros técnicos e não em seus órgãos políticos, se verifica através da supervisão orçamentária e da designação de indivíduos para as funções 
centrais de coordenação de atividades de natureza técnica. Em certas ocasiões, o corpo técnico dessas agências, por alguma razão fortuita, pode vir a gerar e desenvolver ideologias, conceitos e sugestões de política que são consideradas contrárias aos objetivos estratégicos das estruturas hegemônicas. Quando isto ocorre, desencadeia-se um processo de ridicularização (como aconteceu com a teoria da deterioração dos termos de intercâmbio, hoje reconhecida pelo próprio FMI como "correta”), de ataque frontal e, eventualmente, de estrangulamento financeiro ou de substituição das lideranças de seus quadros. Esse processo ocorreu com a Comissão Econômica para América Latina (CEPAL), estigmatizada devido à sua teoria estruturalista e desenvolvimentista da América Latina, e com a United Nations Educational, Scientific and Cultural Organization (UNESCO), quando esta abriu os debates e estudos sobre a "nova ordem da informação". Com a United Nations Conference on Trade and Development (UNCTAD) e a United Nations Industrial Development Organization (UNIDO) ocorreram e ocorrem processos semelhantes de descrédito.

As análises, as interpretações da realidade econômica (mas também social e política, em menor mas em crescente grau), as sugestões de política, em especial no que diz respeito às relações dos Estados da periferia com as estruturas hegemônicas, são assimiladas pelos meios de comunicação dos países periféricos e por suas elites co-optadas e apresentadas às populações periféricas como científicas, imparciais, benéficas e “únicas”. Essas interpretações, como foi dito, ao se chocarem com a realidade são esquecidas, minimizadas ou ridicularizadas até pelos mesmos indivíduos ou agências que as haviam formulado e divulgado.

No esforço de garantir a participação dos países da periferia na aceitação dos resultados das negociações, a Rodada Uruguai, do General Agreement on Tariffs and Trade (GATT), foi apresentada pelas agências internacionais como um exercício que beneficiaria principalmente os países da periferia, pois eliminaria o unilateralismo americano e abriria os mercados dos países desenvolvidos. Hoje, não só o unilateralismo americano permanece como as mesmas agências internacionais relatam que os grandes beneficiários da Rodada Uruguai foram os países altamente industrializados. As políticas neoliberais mexicanas e, em especial, o Presidente Salinas de Gortari, foram apresentados pelas mesmas agências como modelos de política e de estadista a serem seguidos e imitados por todos os governantes e Governos da periferia que desejassem ingressar no Primeiro Mundo. Após a débâcle mexicana, as agências internacionais desenvolveram amplo esforço de reinterpretação, passando a sugerir que a crise do México teria sido a crise não de suas políticas econômicas mas, sim, de seu sistema político; que as agências internacionais teriam "alertado" o Governo mexicano para seus “erros” com grande antecedência e que a culpa pela crise e pelo fracasso do programa foi da equipe econômica mexicana. Em novembro de 1997, em plena crise dos “tigres”, o Diretor Geral do Fundo Monetário Internacional declarou à imprensa que os modelos 
econômicos asiáticos haviam "passado de moda”. Porém, apenas dois meses antes o relatório do FMI (assim como os relatórios das demais agências) apresentavam as economias asiáticas como modelos a serem seguidos por todos os países da periferia, o que era repetido pelos meios de comunicação acriticamente.

A quarta estratégia: a formação de elites

A formação, nos países da periferia, de elites e de quadros simpáticos e admiradores das estruturas hegemônicas de Poder é a quarta estratégia essencial de sua preservação. Os programas de difusão cultural, de bolsas de estudo, de pesquisadores visitantes, de visitas de personalidades políticas e de formadores de opinião são instrumentos utilizados amplamente pelos países que integram aquelas estruturas. Tais programas, patrocinados por aqueles países, estão voltados em especial para suas zonas geográficas tradicionais de influência ou para seus antigos impérios coloniais, como a França em relação à África; os Estados Unidos em relação à América Latina; a Inglaterra em relação à Commonwealth; a Alemanha em relação à Europa Central e Oriental. As instituições que organizam tais programas apresentam suas atividades como sendo de caráter exclusivamente cultural, científico e tecnológico, cujo objetivo seria aproximar os povos, cooperar para o bom entendimento entre os Estados e preservar a paz.

No entanto, e é natural que assim ocorra, nem todos mas, um grande número dos indivíduos que participam de tais programas vêm a desenvolver sentimentos de simpatia em relação ao estilo de vida, ao modo de ver o mundo e as relações entre aquelas estruturas e a periferia e, finalmente, quanto às políticas que as primeiras propõem para resolver as questões e as crises internacionais. Tais indivíduos se tornam elementos de grande importância para as estratégias de preservação das estruturas hegemônicas de Poder na medida em que venham a ocupar posições de destaque na vida pública e privada dos países da periferia.

\section{A quinta estratégia: a difusão ideológica}

Finalmente, o cotidiano da difusão ideológica das políticas de preservação e expansão das estruturas hegemônicas de Poder se verifica pelo uso dos meios de comunicação de massa. Os meios de comunicação de massa se tornaram gigantescas empresas e passam pelo mesmo processo de concentração e de globalização por que passam as empresas dos demais setores industriais e de serviços. Sua estreita vinculação e relação de interdependência com as empresas de publicidade e, portanto, com os interesses econômicos das grandes corporações, multinacionais ou não, dos países centrais fazem com que tenham se tornado, além de defensores da liberdade de expressão e de opinião dos próprios meios de comunicação, defensores dos interesses e das visões do mundo geradas naquelas estruturas hegemônicas. 
Os meios de comunicação atuam sob distintas formas e em distintos níveis na estratégia de difusão ideológica dos interesses das estruturas hegemônicas de Poder. Em primeiro lugar, difundem, de uma forma geral, o modo de vida e de pensar daquelas sociedades, por meio de representações dramáticas da realidade atual, do passado e, até, do futuro. Nesta área, tem especial importância o cinema, que reconstrói para a grande massa a história humana, constrói o futuro e apresenta "interpretações” dos temas mais importantes da sociedade. São, de um lado, os filmes históricos e os de ficção científica ${ }^{5}$ e, de outro, os filmes de ficção sobre o modo de vida e sobre as questões da existência individual no mundo de hoje: o amor, a vingança, as relações de trabalho, a criminalidade, a política, etc. Influenciam eles os padrões de comportamento das grandes massas e constróem os estereótipos sobre essas questões.

Em segundo lugar, os meios de comunicação de massa, de forma diferente, quer se trate da televisão, do rádio ou da imprensa, entretêm e quase monopolizam a atenção do grande público. O grande público tem sua atenção desviada do debate dos temas políticos e econômicos relevantes pelos programas de televisão ou pelas notícias de imprensa sobre esportes, aventuras, crime, violência, sexo, música, vida íntima das personalidades etc., enquanto tais meios difundem uma campanha permanente e sutil de descrédito de toda atividade política, a qual tende a ser apresentada como corrupta, corruptora e inútil para a sociedade, em especial nos países da periferia, mas não somente neles.

Em terceiro lugar, em diversos níveis de detalhe e de sofisticação, desde o noticiário em "pílulas” do rádio e da TV até os artigos da imprensa cotidiana e das revistas noticiosas, os meios de comunicação difundem os modelos de pensamento considerados aceitáveis naquele momento pelas estruturas hegemônicas e promovem a defesa das iniciativas políticas, militares e econômicas dos países que as integram.

\section{As estruturas e o cenário internacional}

As estruturas hegemônicas desenvolvem suas estratégias de preservação e expansão de Poder em um cenário internacional que elas, ao mesmo tempo, criam e de que, ao mesmo tempo, sofrem os seus efeitos. Não caberia neste artigo uma análise detalhada de cada fenômeno que caracteriza o cenário internacional, mas apenas indicar alguns aspectos daqueles que consideramos mais relevantes.

\section{O cenário econômico}

Quanto ao trabalho, os grandes fenômenos são as transformações demográficas e os movimentos de população. As transformações resultam da redução da taxa de natalidade enquanto o avanço científico e tecnológico diminui a 
taxa de mortalidade e, assim, aumenta a expectativa de vida. A redução abrupta da taxa de crescimento demográfico leva ao envelhecimento relativo da população, com conseqüências sobre o sistema previdenciário, sobre a situação fiscal dos Estados e sobre a taxa de poupança. As pressões migratórias da periferia para o centro, decorrentes de conflitos armados e da estagnação econômica, bem como a perspectiva de grandes migrações decorrentes da desintegração de Estados, são o segundo fenômeno que "ameaça” os mercados de trabalho no centro e geram tendências protecionistas e xenófobas.

A aceleração do progresso tecnológico, em especial na área de tecnologia da informação, vem transformando radicalmente os bens de capital e reorganizando a gestão empresarial. Os avanços constantes e rápidos da microeletrônica e da tecnologia da informação têm tornado a unidade típica de produção industrial (ou de serviços modernos) mais "intensiva” de capital, com efeitos sobre o mercado de trabalho, de difícil assimilação a curto e médio prazo.

Por outro lado, a filosofia neoliberal e a redução da regulamentação dos mercados e da atividade econômica em geral, de um lado, acelera a deterioração do meio ambiente e o esgotamento de recursos naturais, em especial na periferia e, de outro lado, permite a concentração do capital em cada mercado, através de fusões e aquisições, e o acumula, cada vez mais, nos países centrais em relação à periferia.

A desregulamentação, em especial das atividades financeiras, globalizou os mercados de capitais. As políticas econômicas recessivas no centro, e as políticas de crescimento econômico na periferia, baseadas na poupança externa, na abertura comercial e no endividamento externo agressivo, geram a necessidade de políticas de juros altos na periferia. Ficam criadas, assim, as condições para a circulação de capitais especulativos de um mercado periférico para outro. Tais capitais permitem, de início, uma temporária e artificial estabilidade econômica, seguida pela necessidade de realização dos lucros que leva à crise cambial e econômica, à desestruturação da economia, ao retrocesso do nível de vida da população e ao agravamento da concentração de renda e das disparidades sociais. Os episódios dos últimos anos, a começar da crise mexicana em 1994 até a recente crise dos “tigres” asiáticos, no final de 1997, são exemplos deste processo.

Sendo os capitais especulativos originários do centro, tende a prevalecer e permanecer, nos governos daqueles países e nas agências internacionais, a filosofia de firme oposição a qualquer iniciativa de regulamentação dos mercados de capitais que reduza sua volatilidade e, ao contrário, prevalecem as posições agressivamente favoráveis à completa liberdade de movimentação de capitais, em especial a curto prazo. Os capitais são especulativos devido às políticas econômicas e não a despeito das políticas econômicas exercidas pelos países centrais e da periferia.

A deterioração do meio ambiente e a crescente escassez de recursos naturais, em especial água e, em breve, petróleo, leva à convicção de ser impossível 
reproduzir na periferia os atuais padrões de consumo do centro. Esta convicção está por trás da ideologia do “desenvolvimento sustentado" que, em primeiro lugar, desvia a atenção da opinião pública da necessidade e da obrigação dos países centrais em reduzir seus elevados padrões de consumo de recursos e de poluição e, assim, permite ao centro mantê-los. Em segundo lugar, recomenda que a periferia deva contentar-se em permanecer em seus atuais baixos padrões de consumo e encetar a tarefa paradoxal e dificílima de imaginar e executar estratégias de “desenvolvimento sustentado", o que exigiria a intervenção do Estado em ambientes políticos nacionais e internacionais em que predomina o pensamento econômico liberal. Gera-se, assim, um preconceito antiindustrial nos Estados da periferia, que contribui para fortalecer indiretamente as estratégias que insistem em fundamentar o desenvolvimento em vantagens comparativas estáticas, com base na dotação de recursos naturais, com efeitos óbvios sobre as possibilidades de desenvolvimento a longo prazo.

Não se trata de advogar estratégias de desenvolvimento predatórias e poluidoras, mas, sim, de chamar a atenção para a contradição entre, de um lado, a advocacia dos países do centro em favor da mais ampla liberdade para as forças de mercado (e para a atividade empresarial) e da redução do poder regulamentador do Estado e, de outro lado, a advocacia e pressão do centro pela adoção na periferia de políticas eficazes de desenvolvimento sustentado, inclusive com a ameaça de sanções e restrições ao comércio de bens produzidos de forma "agressiva" ao meio ambiente, através de "cláusulas ambientais" aplicadas unilateralmente ou pela OMC. Na realidade, a grave deterioração ambiental na periferia exige maior intervenção do Estado, por meio de uma política industrial ativa, que estabeleça restrições a certas tecnologias e oriente a localização de indústrias através de políticas regulamentadoras, de crédito e de subsídios, ainda que tal política venha, de certa forma, a contrariar o que resultaria do livre jogo das forças de mercado e os interesses de curto prazo das empresas privadas, que não levam em consideração o custo social ou ambiental de suas atividades.

As políticas neoliberais, que se fundamentam na idéia de mercados de livre concorrência que se auto-regulariam e regulariam a economia (e até o sistema político), promovem a desregulamentação e a desmontagem nos países centrais da legislação e das agências "antitrust”. Essa desregulamentação e desmontagem permite que as fusões e aquisições façam aparecer gigantescas empresas em cada mercado, que se tornam cada vez mais distantes das condições que caracterizam a livre concorrência. Essas gigantescas empresas, que atuam em âmbito mundial, ao ingressar nos mercados da periferia assumem necessariamente neles posições dominantes, capazes de determinar os preços e auferir lucros extraordinários, o que leva a situações oligopolísticas com as conseqüências conhecidas para o consumidor, o cidadão comum e o trabalhador, portanto, para a maioria da população. 
O cenário econômico mundial se caracteriza pela interação entre, de um lado, um quadro estrutural de desemprego, ${ }^{6}$ concentração de capital e de renda, degradação do meio ambiente, escassez de recursos naturais, grande volatilidade da massa enorme de capitais especulativos e, de outro lado, um quadro conjuntural de políticas econômicas clássicas, aplicadas no centro das estruturas hegemônicas, de natureza recessiva, baseadas na estabilidade quase absoluta da moeda, no equilíbrio fiscal, na desregulamentação agressiva dos mercados, na redução do Estado. Esta interação tende a agravar aqueles aspectos negativos do quadro estrutural da economia mundial, com conseqüências para as possibilidades de desenvolvimento e de estabilidade política e econômica dos países de periferia.

Essas políticas conjunturais neoliberais adotadas no centro quando “impostas” aos países da periferia, através de pressões "legais”, como as negociações na OMC, ou ilegítimas e ilegais, como as ameaças e "retaliações" da Lei de Comércio dos Estados Unidos, têm efeitos ainda mais graves pela exigência adicional de políticas de abertura comercial e financeira, em um conjunto de circunstâncias que tende a acentuar as disparidades internas e externas que definem a situação de subdesenvolvimento.

\section{O cenário político}

Os principais fenômenos políticos são a reorganização territorial, a concentração de poder militar, os efeitos da publicidade e da mídia sobre a política e o aumento da "demanda democrática”.

A reorganização territorial se verifica pela desintegração de Estados, como ocorreu com a União Soviética, a Iugoslávia e a Checoslováquia, pela pressão de tendências separatistas (Reino Unido, Canadá, Espanha, Itália, Rússia) e pela formação de novas entidades, inicialmente econômicas, mas com perspectivas de transformação política a médio ou a longo prazo, tais como a União Européia, o Mercosul e o NAFTA.

A concentração de poder militar decorre da natureza crescentemente científica e tecnológica do equipamento militar moderno. Como a pesquisa em ciência e tecnologia avançadas se caracteriza pelo elevado custo, pela necessidade de uma base industrial capaz de testar seus avanços, pela aleatoriedade de resultados e pelas economias de escala, somente poucos países altamente desenvolvidos são capazes de empreender tais programas de pesquisa militar, cujos resultados se concretizam na produção de armamentos sofisticados, de grande eficácia e poder destrutivo, o que vem a resultar na concentração de poder militar.

O desenvolvimento das técnicas de pesquisa de opinião e de publicidade, o rápido desenvolvimento tecnológico da mídia, a modificação dos hábitos sociais trazida pela televisão e, mais recentemente, pelo computador, aumentaram a 
influência do poder econômico sobre o sistema político e transformaram as campanhas e debates políticos em programas de "marketing de produtos”, sem confronto real de ideais, de idéias e de propostas políticas.

\section{Objetivos estratégicos dos grandes países periféricos}

Devido às suas características que os distinguem radicalmente dos pequenos e médios países da periferia, os grandes países periféricos enfrentam graves dilemas para a definição e execução de seus objetivos estratégicos neste quadro de profundas transformações econômicas e políticas do cenário mundial.

Assim como o objetivo estratégico das estruturas hegemônicas de Poder é a sua própria preservação e expansão (devido aos benefícios que os países, que em seu centro se situam, delas derivam) os objetivos estratégicos finais dos grandes países periféricos seriam ou participar dessas estruturas hegemônicas de forma compatível com suas potencialidades ou promover a redução de seu grau de vulnerabilidade diante dessas estruturas.

Essa visão se contrapõe à visão que advoga, de forma implícita ou explícita, que os grandes países periféricos estão fadados a permanecer na periferia por sua própria incapacidade ou por não terem poder suficiente para vir a participar das estruturas hegemônicas de Poder ou até mesmo para reduzir sua vulnerabilidade diante delas.

Três deveriam ser os objetivos-meio dos grandes países periféricos, como a Índia e o Brasil. O primeiro desses objetivos é a redução de sua vulnerabilidade externa; o segundo é a redução de suas desigualdades internas; e, o terceiro é a construção de sistemas democráticos reais. Neste artigo, a apresentação sumária desses objetivos tem um viés brasileiro de interpretação; porém, acredita-se que, em grande medida e devido a seu grau de generalidade, se apliquem eles, com as distinções cabíveis, à situação da Índia.

\section{Vulnerabilidades externas}

A redução das vulnerabilidades externas é essencial para garantir uma trajetória sustentada de desenvolvimento político e econômico (inclusive do ponto de vista ambiental), isto é, sem estarem sujeitos a sociedade e o Estado a choques econômicos abruptos por força de eventos externos que, apesar de se poder dizer estarem fora de seu controle, podem ser previstos por uma política econômica cautelosa. Tais choques econômicos afetam a capacidade de investimento da economia, e, portanto, os programas de preenchimento das "lacunas" nas cadeias produtivas, de redução dos desequilíbrios regionais, de ampliação do emprego e de aumento da produtividade e, indiretamente, de superação de tensões políticas e sociais. 
A redução da vulnerabilidade econômica externa somente pode ocorrer se a estratégia de desenvolvimento se basear principal (mas não exclusivamente, como é óbvio) no mercado interno. Tal implica o esforço consistente de aumento da poupança pública e privada; a busca de estratégias de plena utilização dos fatores de produção disponíveis através de políticas tecnológicas (e, portanto, de emprego) diferenciadas; o esforço consistente de desenvolvimento científico e tecnológico, com a importação de mão-de-obra altamente qualificada e de fortalecimento dos centros de pesquisa e dos centros de formação de pessoal; o esforço de desenvolvimento da indústria de bens de capital, que é o setor através do qual se introduzem as inovações tecnológicas no sistema produtivo; uma política de comércio exterior que maximize o uso das reservas cambiais escassas para fortalecer o sistema produtivo interno e não para promover a criação de hábitos de consumo baseados na importação de bens supérfluos, financiados pela entrada de capitais especulativos; e, finalmente, uma política cambial que contribua para a expansão das exportações e para a proteção das indústrias novas. Somente esse enfoque estratégico reduziria a causa central da vulnerabilidade que é a elevada e crescente dívida externa e os constrangimentos que causa ao tornar necessária uma política de juros elevados e ao provocar uma sensação de "falta de credibilidade” permanente na estabilidade da moeda nacional.

A redução da vulnerabilidade política externa depende da definição de estratégias prioritárias conjuntas de política internacional com os outros grandes países periféricos; do estabelecimento de programas concretos de cooperação econômica e política com os países vizinhos; da redução das vulnerabilidades econômicas externas e da criação de uma capacidade industrial militar própria, ainda que apenas para equipamentos militares convencionais, como forma de estimular a pesquisa tecnológica e de adquirir gradualmente o conhecimento necessário a etapas superiores.

A redução da vulnerabilidade ideológica externa depende da definição de uma estratégia de comunicação audiovisual que, sem censura e sem orientação ideológica, induza ao fortalecimento da identidade nacional, das instituições nacionais e dos valores da cidadania e da comunidade, necessários a um projeto de desenvolvimento político e econômico que mobilize a população para os esforços e sacrifícios necessários a "escapar da periferia”.

Naturalmente que todas as estratégias e programas de redução da vulnerabilidade externa terão de ser graduais e com uma perspectiva que abranja do curto ao longo prazo. Tais programas sofrerão as mais severas restrições das estruturas hegemônicas de Poder, que se sentirão ameaçadas ou pela perspectiva de eventual ingresso de novos participantes, o que alteraria as relações de poder e a distribuição dos benefícios dentro delas, ou pela maior autonomia daqueles grandes países periféricos em relação à sua influência. 


\section{Disparidades internas}

As disparidades internas ocorrem nos mais distintos setores. A questão crucial não é a existência de disparidades mas, sim, a sua natureza extrema e, em segundo lugar, a percepção daqueles setores da população que se sentem prejudicados quanto às perspectivas de redução dessas disparidades no médio prazo. Caso as perspectivas de redução dessas disparidades sejam percebidas como remotas ou inexistentes, ou caso as perspectivas sejam de agravamento dessas disparidades, a probabilidade de aumento de instabilidade no sistema social e territorial se torna cada vez maior.

A redução das desigualdades internas extremas tem de se iniciar por um programa articulado dirigido a reduzir as disparidades entre as distintas regiões do país, isto é, entre a qualidade de vida atual e potencial dos habitantes dessas regiões. O futuro de qualquer país como tal não existe, ou fica em extremo prejudicado, caso se agravem as rivalidades regionais em um contexto de escassez de recursos, de instabilidade internacional e de internacionalização da economia, o que pode corresponder a um enfraquecimento político dos laços que unem as distintas regiões do país, devido ao enfraquecimento dos laços que constituem o mercado e o sistema político interno. A questão grave que hoje se coloca é que certas políticas econômicas de corte neoliberal (ainda que seus formuladores e executores não aceitem que elas sejam assim denominadas), assim como certas estratégias políticas de descentralização de competências do Estado tendem a agravar as disparidades econômicas e políticas e, portanto, a instabilidade social, política e, até, territorial.

As disparidades internas de ordem econômica se refletem nos índices de concentração crescente de renda (e de riqueza), tanto entre as regiões como entre indivíduos. ${ }^{7}$ A redução das desigualdades internas não pode ocorrer através de programas assistencialistas que dependam da boa vontade e da generosidade dos indivíduos, das empresas e das organizações sociais, por mais meritórios que sejam tais programas. A redução dessas desigualdades depende da redistribuição de renda e de riqueza efetuada pelo Estado com a adoção de um sistema fiscal progressivo e direto que financie programas de serviços públicos nas áreas de saneamento básico, saúde, transporte, educação e justiça (direitos humanos, a começar pelos direitos dos presidiários) que efetivamente beneficiem parcelas crescentes da população desprivilegiada. Tais programas somente terão efeito se redistribuírem renda de forma permanente. Para que isto ocorra, é necessário que sejam acompanhados por políticas diferenciadas de geração de empregos que permitam o aumento da produtividade (e dos rendimentos) do trabalho. Somente o aumento da produtividade, caso esta seja apropriada em parte pelo trabalho, pode aumentar de forma permanente o nível de renda de um indivíduo.

Os argumentos sobre as dificuldades e até a inconveniência em definir e implantar programas deste tipo pelo Estado não têm relevância. O fato importante 
é que são eles possíveis e urgentes e que caso não venham a ser adotados as conseqüências dessa omissão serão graves e inevitáveis. Naturalmente, tais programas somente geram resultados a médio prazo, mas a percepção de sua existência pelas populações beneficiadas é essencial, assim como a própria participação dessas populações em sua elaboração.

No quadro das disparidades internas, adquire grande importância o papel da mídia. Do ponto de vista econômico, a mídia relevante, isto é, a que atinge grande audiência, na imprensa, na radiodifusão, mas, em especial, na televisão, está organizada como grande empresa com finalidade lucrativa. Suas vinculações com o setor produtivo privado, através das agências de publicidade, fazem com que elas sejam acima de tudo, veículos de difusão de anúncios comerciais e, portanto, indutores do consumo. Esta indução ao consumo vai de encontro à necessidade de aumentar a taxa de poupança interna com vistas a aumentar a taxa de investimento, sem dependência excessiva da poupança externa. Do ângulo político, e no caso brasileiro, os meios de comunicação de massa, em especial a televisão e o rádio, são concessões do poder público e, muitas vezes, vinculados às agências do Estado por operações de empréstimo. Do ângulo social, a televisão, em especial, tem-se permitido uma exploração excessiva da violência, do individualismo e do sexo, com repercussões sobre os padrões de comportamento da juventude em geral e dos segmentos da população mais sensíveis a tal exploração.

Ao lidar com os meios de comunicação, imediatamente se coloca a questão da liberdade de expressão e de seus limites, isto é, da conveniência política e ética da censura. Sendo os meios de comunicação, em especial a televisão, concessões do poder público e, ao mesmo tempo, empresas voltadas para o lucro (e, em extremo, lucrativas), e tendo em vista a situação social, econômica e política seria perfeitamente correto e possível para os Governos, sem utilizar a censura, estimular comportamentos de programação condizentes com tal situação. No que diz respeito à incitação à violência e à exploração de cenas de sexo e de cenas aviltantes do indivíduo, não há dúvida de que a legislação penal poderia ser perfeitamente aplicada aos responsáveis por tais programas.

\section{A construção da democracia real}

O terceiro objetivo estratégico dos grandes países periféricos é a construção da democracia real e não apenas a preservação dos regimes democráticos formais e precários que existem hoje. Os grandes óbices dos sistemas políticos nos grandes países periféricos são a influência do poder econômico e os custos do processo político, o baixo nível cultural e de informação política de vastas camadas da população, sua exploração demagógica e o uso dos organismos do Estado e do processo legislativo para fins privados. 
O grande dilema da democracia e do capitalismo é que, na democracia liberal, cada cidadão tem um voto, enquanto que, na economia de mercado, cada consumidor tem tantos "votos" quanto a sua renda. Assim a capacidade de escolher, de influir nas decisões do sistema econômico, tanto no que diz respeito às decisões de consumo como às decisões de investimento, estão “descasadas” da capacidade do mesmo indivíduo de influir sobre as decisões do sistema político.

O sistema de voto censitário na democracia liberal durante décadas "resolveu” esta questão, fazendo com que somente os proprietários, ou aqueles que dispusessem de uma certa renda anual, fossem capazes de votar e de serem votados. Na medida em que os processos políticos substituíram o voto censitário pelo sufrágio universal, isto é, pelo voto do indivíduo masculino adulto e, mais tarde, estenderam o sufrágio ao sexo feminino, o "dilema” anterior se colocou novamente.

Quanto mais concentradas a renda e a riqueza, maior o descompasso entre o sistema econômico e o sistema político e maior a influência do poder econômico na política para garantir que o peso dos interesses econômicos corresponda à sua influência no sistema de decisão política, inclusive para que aqueles interesses fiquem salvaguardados.

Assim, a principal característica da democracia no mundo atual é a influência do poder econômico sobre a política, através das modernas técnicas de publicidade, de pesquisas de opinião e do uso da televisão na política.

As modernas técnicas de publicidade, acopladas aos novos hábitos sociais gerados pela televisão, isto é, a fragmentação do discurso lógico e do fluxo de idéias e imagens desconectadas entre si, a eliminação do intercâmbio de idéias e de experiências no seio da família e da comunidade, facilitaram a transformação das campanhas eleitorais em campanhas de promoção de "produtos de consumo político".

As modernas técnicas de pesquisa de opinião, orientadas e fragmentadas por segmentos sociais com interesses comuns permitem a identificação científica das mensagens que os diversos segmentos sociais desejam ouvir, e reduzem o compromisso efetivo dos candidatos com um programa político consistente e com seus eleitores, e impedem o contraste e o debate de idéias.

O custo das campanhas eleitorais pela TV e os sistemas majoritários de eleição, em que os candidatos têm de percorrer extensos territórios, pois as circunscrições eleitorais são muito amplas, ${ }^{8}$ tornam ainda maior a influência do poder econômico na política e nas eleições. A concentração de renda e de propriedade que se verifica na esfera econômica se reproduz na esfera política e torna mais difícil a adoção de medidas de correção das disparidades econômicas, em essencial a desconcentração de renda, pois tais medidas teriam de ser adotadas, em um processo democrático, pelos próprios representantes políticos diretos ou indiretos dos setores que se beneficiam da atual dinâmica de concentração de renda. 
Assim, o fortalecimento da democracia real exige a democratização do processo de escolha de candidatos, com a participação efetiva dos eleitores; a elevação da qualidade da representação popular, através de sistema de candidatos individuais e de listas de candidatos partidários; a redução da dimensão territorial das circunscrições eleitorais; a redução do uso da televisão nas campanhas eleitorais, a democratização do acesso e a proibição do uso de técnicas de propaganda comercial na campanha eleitoral. Todavia, a dificuldade em se implementar tais reformas decorre do próprio fato de que teriam de ser adotadas pelos atuais beneficiários do sistema político e eleitoral em vigor.

\section{Conclusão}

Apesar das extraordinárias diferenças que existem entre o Brasil e a Índia e que foram apresentadas neste artigo, o fato de compartilharem uma série de características e de interesses comuns como grandes países periféricos e o fato de estarem situados em regiões geograficamente distantes e, portanto, de não serem seus interesses diretamente competitivos e conflituosos, criam condições promissoras para a construção de projetos políticos comuns entre a Índia e o Brasil.

Por outro lado, a Índia e o Brasil, na medida em que compartilharem do mesmo objetivo estratégico central de superar sua condição de grandes países periféricos e assim, ou se inserir nas estruturas hegemônicas de Poder ou reduzir sua vulnerabilidade diante dessas estruturas, podem prever que, ao procurarem alcançar tal objetivo, enfrentarão séria resistência dos Estados que, tradicionalmente, integram aquelas estruturas.

Desta forma, a cooperação estratégica entre o Brasil e a Índia, o intercâmbio regular de experiências, a elaboração de projetos e sua execução no campo da alta tecnologia, a articulação de ações de política internacional para defender interesses comuns permitiria potencializar seus recursos, relativamente escassos, e aumentar a probabilidade de êxito no alcance do grande objetivo estratégico de "escapar da periferia”, essencial para garantir às suas populações progresso econômico sustentado, crescente justiça social e o exercício da democracia real.

Maio de 1998

\section{Bibliografia}

ARRIGHI, Giovanni. O Longo Século XX. Chicago: University of Chicago Press, 1982.

BALDWIN, David A.. Economic Statecraft. Oxford: Princeton University Press, 1985. 
CARNES, Mark C. (org.). O Passado Imperfeito: a história do cinema. Rio de Janeiro: Editora Record, 1997.

DEBORD, Guy. A Sociedade do Espetáculo. Rio de Janeiro: Contraponto Editora, 1992.

GILPIN, Robert M.. The Political Economy of International Relations. Princeton: Princeton University Press, 1987.

HOBSBAWN, Eric. Era dos Extremos: o Breve Século XX. São Paulo: Companhia das Letras, 1995.

MCNEILL, William H.. The Pursuit of Power. Chicago: University of Chicago Press, 1982.

SCHURMANN, Franz. The Logic of World Power. New York: Pantheon Books, 1974.

THUROW, Lester. The Future of Capitalism. London: Nicholas Brealey Publishing, 1996.

TUNSTALL, Jeremy. The Media Are American. New York: Pantheon Books, 1974.

\section{Notas}

1 Uma exceção importante é a tradicional cooperação nos foros econômicos internacionais entre as delegações diplomáticas brasileiras e indianas.

2 Isto é, não cria barreiras legais. Isto não quer dizer que não haja preconceito, em especial em relação aos negros, nas classes média e alta, mas não entre as classes pobres, onde há uma menor incidência de preconceito racial.

3 De certa forma, foi o domínio colonial que veio a unificar a Índia como Estado.

4 Os acordos de assistência militar e fornecimento de armas influenciam as concepções políticas estratégicas, o treinamento de oficiais, criam vínculos comerciais e vínculos de interesse e simpatia política.

5 O cinema de Hollywood apresenta as estruturas hegemônicas e, em especial, os Estados Unidos como os líderes científicos e tecnológicos e como os únicos capazes de defender a humanidade nas eventuais "guerras intergalácticas”, como no exemplo do filme Independence Day.

6 A situação de emprego e de expansão da economia nos Estados Unidos deve-se, justamente, à sua posição estratégica no centro das estruturas hegemônicas e de país emissor da moedareserva internacional.

$7 \quad$ No caso do Brasil, tem sua origem na longa vigência do regime escravocrata (que durou trezentos e oitenta e oito anos) e do regime servil dos grandes latifúndios, que durou até recentemente quando se introduziu a legislação de trabalho no campo. E, por sua vez, esta concentração de renda se reflete no sistema político através da extraordinária desigualdade de poder efetivo entre os cidadãos, que são nominalmente iguais. A deficiência de políticas eficazes para superar as desigualdades econômicas, sociais e políticas, torna a população de origem negra (e pobre) sujeita a absorver influências desagregadoras externas e a fortalecer tendências de exclusão e rejeição de integração na sociedade mais ampla.

8 Esta observação é válida para o Brasil. Todavia, a influência do poder econômico nas eleições é um fenômeno que ocorre em ambos os países, em grande escala. 
Resumo

O artigo parte de uma análise das estratégias de perpetuação das estruturas hegemônicas de Poder e dos objetivos mais gerais dos grandes países periféricos (no caso, Brasil e Índia) para, então, propor estratégias para a melhor inserção destes naquelas.

\section{Abstract}

The article goes from an analyses of the perpetuation of the power hegemonic structures and the general goals of the great peripheric countries (in this case, Brazil and India) to suggesting better insertion strategies for these countries on those structures.

Palvras-chave: Estruturas hegemônicas de Poder. Brasil. Índia. Estratégias de inserção.

Key-words: Hegemonic power structures. Brazil. India. Insertion strategies. 